\title{
The Correlations on Coping with Cyberviolence, Attribution Method and Social Support among Middle School Students
}

\author{
Na Young Choi1)
}

\begin{abstract}
The purpose of this study is to compare the level of coping with cyberviolence, attribution methods and social support for middle school students. Structured survey data on coping with cyberviolence, attribution methods and social support on middle school students in City A, South Korea was collected from September, 20th, 2019 to October 25th, 2019. The survey data were analyzed from 257 responses, excluding unreturned or incomplete surveys. Data were analyzed using the Pearson correlation coefficient to identify the significant correlations on coping with cyberviolence, and psychological variables such as attribution methods and social support for middle school students. This study found that technical defense $(\mathrm{r}=.114, \mathrm{p}<.01)$, active response $(\mathrm{r}=.253, \mathrm{p}<.001)$ on cyberviolence had a significant and positive correlation to social support. On the other hand, passive response $(\mathrm{r}=.-154, \mathrm{p}<.001)$, disregard( $\mathrm{r}=-.115, \mathrm{p}<.01)$, and evasion $(\mathrm{r}=-.126, \mathrm{p}<.001)$ on cyberviolence had a significantly inverse correlation to social support. Therefore, this study provided prevention education programs for coping with cyberviolence, a meaningful direction in which further research may take note.
\end{abstract}

Keywords: Cyberviolence, Coping, Attribution, Social Support, Student

\section{Introduction}

\subsection{Background}

Due to the development of high-speed internet, modern people have easier access to virtual environments that extend personal relationships, an ability to express their own thoughts freely and ways to gather information. However, recently it has been noted that excessive internet use has to lead to a rise in cyberviolence and other forms of harassment through the internet[1]. As number of hours spent on the internet and in virtual environments, there has been an increase in damage caused by cyberviolence and cyberviolence in recent years[2].

Damage caused by cyberviolence includes leaking of personal information, discrimination, insulting criticisms, intentional and repetitive harassment and slander among other forms of

Received(April 8, 2020), Review Result(1st: May 21, 2020, 2nd: July 3, 2020), Accepted(July 27, 2020)

1) (Professor) 36729 Gyeongdong-ro(Seongcheon-dong), Andong University, Andong-si, Gyeongsangbuk-do, South Korea

email: choice4na@hanmail.net 
verbal harassment and infringement on other's rights occurring within virtual environments[3]. These forms of damage can last for extended periods of time due to the invisible nature of the attacks that reach far without a physical environment[4].

In particular, cases of cyberviolence among adolescents are increasing day by day and it is slowly becoming a prominent social issue[1]. According to research published by the National Youth Policy Institute of Korea, an astonishing 14.6\% of Korean adolescents experienced some form of cyberviolence, $6.3 \%$ of Korean adolescents admitted to committing some form of cyberviolence and $13.1 \%$ of the adolescents both experience and committed cyberviolence at some point in their lives[5]. In addition, adolescents who are targeted by cyberviolence may also refuse to attend school, perform poorly at school, experience a drop in self-esteem, feel rage and anger among other difficulties hindering normal teenage life[6]. These students may feel worthlessness and lethargy as a result of the internalization of these issues[7], and these issues may further lead to depression, suicide among other negative consequences[8]. Due to the assailants and the victims of cyberviolence experiencing loneliness, a lack of attention and high aggression, cyberviolence has come to the forefront as a serious issue that requires research immediately[8].

According to previously recorded research, a passive coping methods could actually make the issue worse, and the type and the method to cope with cyberviolence by adolescents affects whether the violence continues or not[9]. Since a proper coping mechanism towards cyberviolence could prevent negative effects, a proper approach is very important[10]. Therefore to eradicate cyberviolence, research about an active approach to coping mechanisms and intervention methods for victims of cyberviolence is needed[11].

Cyberviolence as a social issue is being highlighted as of late, due to the majority of middle school students using smartphones and Social Networking Services (SNS)[12]. Thus, to prevent cyberviolence from beginning early, research for early middle school students on coping methods towards cyberviolence is required.

Middle school students are more likely to reduce their exposure to cyberviolence if they receive social support from their peers and, so social support can be a decisive variable of cyberviolence coping methods[10]. Therefore, research focused on the type of coping methods towards cyberviolence and the relationship between social support and other variables could reveal important information about the intervention direction and the types of mechanisms required towards cyberviolence. This study focuses on the relationship between coping method towards cyberviolence and the psychological variables along with social support while looking at the differences between genders, and attempts to build an intervention and prevention 
program based on the results.

\section{Methodology}

\subsection{Study Design}

This study is a descriptive survey study on the relationship between coping with cyberviolence by middle school students and the psychological variables and social support received from their peers.

\subsection{Research Subjects and Data Collection}

The subjects of this study were students at a middle school in City A. To take into consideration the ethical concerns of this study, the study took place from September 20th, 2019 to October $25^{\text {th }}$ of the same year after a thorough explanation and a consent forms were signed by the students. Using the G*Power 3.1.9 program, the statistical significance of the study was $a=.05$ and the statistical power of the study was $1-\beta=.80$ for an effect size of 0.25 . The results of $\mathrm{G}^{*}$ Power 3.1 .9 was 159 subjects. 280 students of this study were collected. Excluding the responses filled out without effort and the meaningless outlier responses, survey data on a total of 257 students were collected.

\subsection{Materials}

\subsubsection{Coping with Cyber Violence}

After modifying the measurement tools on coping with cyberviolence by In Soo Oh, Seo Jeong Kim and Young Eun $\operatorname{Im}(2019)[13], 3$ nursing professors complemented and fit the variables for the purpose of this study. The Cronbach's a value was 0.89 .

\subsubsection{Attribution Method}

Fitting the criterion set by Ji Yeon Song (2016)[14] towards middle school students, 6 questions were attributed towards victims, 4 questions towards the perpetrator and 5 for bilateral errors, for a total of 15 questions in the attribution method section. 3 nursing professors modified and complemented the questions as seen fit for the purpose of this study. A higher score on the 
attribution method scale meant a higher tendency to have a perpetrator attributed personality. This study's Cronbach's a was at 0.9 .

\subsubsection{Social Support}

The 12 Likert attribution questions adapted by Jun Seob Shin and Young Bun Lee(2007)[15]'s 5 point scale was used to create questions fitted towards middle school students. These questions were reviewed and complemented by 3 nursing professors to fit the purpose of this study. This study's Cronbach's a value was at 0.89 .

\subsection{Method of Analysis}

The data collected were analyzed using the SPSS/WIN 22.0 program and the general characteristics, the sample size, percentage, the mean and standard deviation of the students and the cyberviolence coping method were analyzed in this manner. The differences between the general characteristics and the coping methods of cyberviolence were analyzed via t-tests, chi-squared tests. In addition, the relationship between coping methods of cyberviolence was analyzed via Pearson's correlation coefficient.

\section{Results}

\subsection{General Characteristics}

This study collected survey data on 280 middle school students in City A and received 265 responses for a response rate of 94.6\%. Excluding the responses lacking effort and the meaningless responses, a total of 257 subject data was used. The average age of the subjects was 14.3 with 127 male students (49.4\%) and 130 female students (50.6\%). Protestant Christian was the most common religion among the students with 88 students(34.3\%) and the most common economic situation was middle with 99 students $(38.5 \%)([$ Table 1$])$.

[Table 1] General Characteristics according to Gender of Subjects

$(\mathrm{N}=257)$

\begin{tabular}{|c|c|c|c|c|}
\hline \multirow{2}{*}{ Characteristics } & \multirow{2}{*}{ Categories } & Male & Female & \multirow{2}{*}{$\mathrm{N}(\%)$} \\
\hline & & $\mathrm{N}(\%)$ & $\mathrm{N}(\%)$ & \\
\hline \multirow{3}{*}{ Grade } & 1stgrade & $45(17.5)$ & $42(16.3)$ & $87(33.8)$ \\
\hline & 2ndgrade & $39(15.2)$ & $41(16.0)$ & $80(31.2)$ \\
\hline & 3rdgrade & $43(16.7)$ & $47(18.3)$ & $90(35.0)$ \\
\hline
\end{tabular}


http://dx.doi.org/10.47116/apjcri.2020.08.04

\begin{tabular}{lllll}
\hline \multirow{4}{*}{ Religion } & Christians & $42(16.3)$ & $46(18.0)$ & $88(34.3)$ \\
\cline { 2 - 5 } & Catholicism & $33(12.8)$ & $36(14.0)$ & $69(26.8)$ \\
\cline { 2 - 5 } & Buddhism & $18(7.0)$ & $21(8.2)$ & $39(15.2)$ \\
\cline { 2 - 5 } Economic status & Other or None & $34(13.2)$ & $27(10.5)$ & $61(23.7)$ \\
\hline \multirow{3}{*}{ Academic record } & Upper & $38(14.8)$ & $45(17.5)$ & $83(32.3)$ \\
\cline { 2 - 5 } & Middle & $48(18.7)$ & $51(19.8)$ & $99(38.5)$ \\
\cline { 2 - 5 } & Lower & $41(16.0)$ & $34(13.2)$ & $75(29.2)$ \\
\cline { 2 - 5 } & Migh & $36(14.0)$ & $47(18.3)$ & $83(32.3)$ \\
\cline { 2 - 5 } & Low & $49(19.1)$ & $50(19.4)$ & $99(38.5)$ \\
\hline
\end{tabular}

\subsection{The Coping with Cyberviolence according to Gender of Subjects}

After analyzing the subjects and the differences in coping methods towards cyberviolence, a frequency analysis identified that there was a significant difference in methods. In addition, to identify the differences between methods by gender, a chi-squared test noted that there was a significant difference in 8 different mechanisms between genders. Male students coped with cyberviolence through mostly direct attack (11.3\%), active response (10.5\%), disregard (8.6\%), indirect attacks $(5.1 \%)$, technical defense $(3.9 \%)$, passive response $(1.9 \%)$ or evasion $(1.2 \%)$. On the other hand, female students used active response $(10.9 \%)$ the most and also resorted to technical defense $(9.3 \%)$, disregard $(8.2 \%)$, direct attack $(7.4 \%)$, indirect attack $(6.2 \%)$, passive response $(2.7 \%)$, and evasion $(2.3 \%)$ ([Table 2$])$.

[Table 2] The Coping with Cyberviolence according to Gender of Subjects

$(\mathrm{N}=257)$

\begin{tabular}{cccc}
\hline \multirow{2}{*}{ Characteristics } & Male & Female & \multirow{2}{*}{$\mathrm{N}(\%)$} \\
\cline { 2 - 4 } & $\mathrm{N}(\%)$ & $\mathrm{N}(\%)$ & $48(18.7)$ \\
\hline \hline DA & $29(11.3)$ & $19(7.4)$ & $29(11.3)$ \\
\hline IA & $13(5.1)$ & $16(6.2)$ & $12(4.7)$ \\
\hline PR & $5(1.9)$ & $7(2.7)$ & $55(21.4)$ \\
\hline AR & $27((10.5)$ & $28(10.9)$ & $43(16.7)$ \\
\hline Ig & $22(8.6)$ & $21(8.2)$ & $9(3.5)$ \\
\hline Ev & $3(1.2)$ & $6(2.3)$ & $34(13.2)$ \\
\hline TD & $10(3.9)$ & $24(9.3)$ & $257(100)$ \\
\hline \hline Total & $127(49.4)$ & $130(50.6)$ & \\
\hline$x^{2}(p)$ & & & \\
\hline
\end{tabular}

$\mathrm{DA}=$ Direct Attack IA=Indirect Attack PR=Passive Response $A R=A c t i v e$ Response $I g=I g n o r e ~ E v=E v a s i o n$ TD=Technical Defense 


\subsection{The Relationship between Coping with Cyberviolence, Attribution Method and Social} Support

The study subjects' results on the relationship between coping with cyberviolence and the attribution method and social support is shown in [Table 3]. In the situation of cyberviolence and technical defense coping method, active response $(\mathrm{r}=2.10, \mathrm{p}<0.001)$, perpetrator attribution $(\mathrm{r}=.139, \mathrm{p}<.01)$, social support $(\mathrm{r}=.114, \mathrm{p}<.01)$ had a statistically significant positive relationship, and victim attribution $(\mathrm{r}=-.113, \mathrm{p}<.01)$ had a negative relationship. Thus, it can be concluded from the results that as one uses technical defense more, social support is increased. This tells us that the victim is more likely to believe that cause of cyberbullying is not the victim but the perpetrator.

For passive responses to cyberviolence, disregard $(\mathrm{r}=.413, \mathrm{p}<.001)$, evasion $(\mathrm{r}=.537, \mathrm{p}<$ $.002)$, victim attribution $(\mathrm{r}=-1.86, \mathrm{p}<.001)$, depression $(\mathrm{r}=.105, \mathrm{p}<.05)$ had a significant positive relationship and active response $(\mathrm{r}=-.110, \mathrm{p}<.01)$, perpetrator attribution $(\mathrm{r}=-.167$, $\mathrm{p}<.001)$, social support $(\mathrm{r}=.-154, \mathrm{p}<.001)$ had a significant negative relationship. These results lead to the conclusion that as one uses passive responses due to cyberviolence, disregard, evasion and depression is likely to be increased while social support is lowered. Thus, the victim is likely to believe that the cause of cyberviolence is not the perpetrator but the victim.

For active responses to cyberbullying, perpetrator attribution $(\mathrm{r}=.266, \mathrm{p}<.001)$, social support $(r=.253, p<.001)$ had significant positive relationships with active responses and victim attribution $(\mathrm{r}=-.134, \mathrm{p}<.01)$, and depression $(\mathrm{r}=-.121, \mathrm{p}<.01)$ had significant negative relationships instead. This leads us to the conclusion that using an active response to cyberbullying will lead to higher social support, lower depression. Thus, the victim is likely to be attribute the cause of cyberviolence to the perpetrator instead of the victim.

For disregarding instances of cyberviolence, evasion $(\mathrm{r}=.652, \mathrm{p}<.001)$, victim attribution $(\mathrm{r}$ $=.112, \mathrm{p}<.01)$, depression $(\mathrm{r}=.102, \mathrm{p}<.05)$ had significant positive relationships and social support $(\mathrm{r}=-.115, \mathrm{p}<.01)$ had a negative relationship. This leads to the conclusion that the disregarding coping method towards cyberviolence leads to evasion, depression and lower social support. Thus, the victim will likely attribute the cause of cyberviolence to himself or herself.

For using the evasion coping method towards cyber violence, with victim attribution $(\mathrm{r}=$ $.178, \mathrm{p}<.001)$ there was a significant positive relationship, however there was a negative relationship with perpetrator attribution $(\mathrm{r}=-.104, \mathrm{p}<.05)$, and social support( $\mathrm{r}=-.126, \mathrm{p}<.001)$. This leads to the conclusion that an evasion mechanism approach to cyber violence will lead to 
lower social support and thus the victim is likely to attribute the cause of cyberviolence to the victim himself or herself instead of the perpetrator.

[Table 3] The Correlations on Coping with Cyberviolence, Attribution Method and Social Support among Middle-school Students

$(\mathrm{N}=257)$

\begin{tabular}{|c|c|c|c|c|c|c|c|c|c|c|}
\hline & TD & PR & $\mathrm{AR}$ & Ig & $\mathrm{Ev}$ & VA & PA & TA & De & SS \\
\hline TD & 1 & .078 & $.210^{* * *}$ & .061 & .052 & $-.113^{* *}$ & $.139^{* *}$ & .065 & -.020 & $.114^{* *}$ \\
\hline PR & & 1 & $-.110^{* *}$ & $.413^{* * *}$ & $.537^{* * *}$ & $.186^{* * *}$ & $-.167^{* * *}$ & -.008 & $.105^{\star}$ & $-.154^{* * *}$ \\
\hline AR & & & 1 & -.054 & -.071 & $-.134^{* *}$ & $.266^{* * *}$ & .047 & $-.121^{* *}$ & $.253^{* * *}$ \\
\hline $\mathrm{Ig}$ & & & & 1 & $.652^{* * *}$ & $.112^{* *}$ & -.072 & .031 & $.102^{*}$ & $-.115^{* *}$ \\
\hline Ev & & & & & 1 & $.178^{* * *}$ & $-.104^{*}$ & .020 & .071 & $-.126^{* * *}$ \\
\hline VA & & & & & & 1 & $-.150 * * *$ & $-.332^{* * *}$ & $.106^{*}$ & $-.165^{* * *}$ \\
\hline PA & & & & & & & 1 & $.196^{* * *}$ & -.032 & $.196^{* * *}$ \\
\hline TA & & & & & & & & 1 & $.091^{*}$ & $.105^{*}$ \\
\hline De & & & & & & & & & 1 & $-.311^{* * *}$ \\
\hline SS & & & & & & & & & & 1 \\
\hline
\end{tabular}

$\mathrm{TD}=$ Technical Defense $\mathrm{PR}=$ Passive Response $\mathrm{AR}=$ Active Response Ig=Ignore Ev=Evasion VA=Victim Attribution PA=Perpetrator Attribution TA=Two-sided Attribution De=Depression SS=Social Support

\section{Discussion}

For the subjects of this study, after studying the differences between males and females, it seemed that male students were more likely to get involved in direct attack (11.3\%), and direct response (10.5\%). Female students were more likely to be involved in using active response $(10.9 \%)$, technical defense $(9.3 \%)$, disregard $(8.2 \%)$, direct attack $(7.4 \%)$. According to research done by Se Ri Han(2007)[16] male students tend to get involved in inflicting direct and external attacks and female students prefer indirect attacks as opposed to direct attacks. However in this study, it is observed that female students participate in active responses but get involved less in direct attacks (7.4\%) when compared to male students $(11.3 \%)$. Thus, more research is required on the factors of direct attacks as a response to cyberviolence and more studies must be done to analyze and understand the division between these direct attacks.

After analyzing the relationship between coping with cyberviolence, the attribution method and the social support, there seems to be a tendency for the victim to attribute the root cause of cyberviolence to himself or herself when the victim uses passive responses $(r=-1.86, p$ 
$<.001)$, disregard $(\mathrm{r}=.112, \mathrm{p}<.01)$ and evasion $(\mathrm{r}=.178, \mathrm{p}<.001)$. Therefore, there needs to be an intervention education program to teach the victims of cyberviolence otherwise. In addition, there was a significant positive relationship between technical defense $(r=.114, p$ $<.01)$, active response $(\mathrm{r}=.253, \mathrm{p}<.001)$ and social support, and on the other hand, there was a significant negative relationship between passive response $(r=-.154, p<.001)$, disregard $(r=$ $-.115, \mathrm{p}<.01)$, evasion $(\mathrm{r}=-.126, \mathrm{p}<.001)$ and social support. This gives us the conclusion that victims who utilize passive response, disregard and evasion require a prevention education program to strengthen social support and provide intervention to respond against cyberviolence actively.

This study confirms the differences between responding to cyberviolence by genders in middle school students along with the relationship between responses to cyberviolence, attribution method and social support. This study found meaningful results that led to the conclusion that a catered education program for cyberviolence victims that utilize passive response, disregard and evasion to strengthen their social support is necessary to provide effective coping methods and responses towards cyberviolence.

\section{References}

[1] I. H. Lee, The effects of Ambivalence over emotional expression of adolescents on the cyber verbal bullying: mediating effect of aggression, Catholic University, Master's Thesis, (2014)

[2] H. S. Choi, The Study of the Elementary Senior Years' Communication Using Mobile Social Network Service, Gwangju National University of Education, Master's Thesis, (2015)

[3] N. E. Wilard, Safe and Responsible Use of the Internet: A Guide for Educators, http://www.csriu.org/onlinedocs/pdf/suri/entire.pdf, Mar 30 (2005)

[4] S. S. Im, A Study on the Situation of Youth Cyberbullying and Measures to Prevent It, Korea: Korea Agency for Digital Opportunity and Promotion, (2013)

[5] S. R. Bae, N. S. Park, K. H. Back, E. H. Go, Juvenile delinquency in cyber space, Korea: National Youth Policy Institute, (2017)

[6] S. Hinduja, J. W. Patchin, Cyberbullying: exploratory analysis of factors related to offending and victimization, Deviant Behavior, (2009), Vol.29, No.2, pp.1-29.

[7] Völlink, Bolman, Dehue, Jacobs, Coping with Cyberbullying Differences Between Victims, Bully-victims and Children not Involved in Bullying, Journal of Community \& Applied Social Psychology, (2013), Vol.23, No.1, pp.7-24.

[8] Y. O. Cho, The Impact of Cyber Bullying Victim Experience and the Influence of Mediating Effect of 
Depression on Delinquent Behaviors, Korean Journal of Youth Studies, (2013), Vol.20, No.10, pp.117-142.

[9] Y. J. Park, A. H. Kim, The Effects of the Coping Behavior of Stress and the Korean Parent-Adolescent Affective Bonding for the Problem Behavior of Adolescents, The Research Institue of Korean Education, (2012), Vol.30, No.3, pp.1-18.

[10] Raskauskas, Huynh, The process of coping with cyberbullying: A systematic review, Aggression and Violent Behavior, (2015), Vol.23, pp.118-125. DOI: https://doi.org/10.1016/j.avb.2015.05.019

[11] E. J. Choi, The victims' reactions in victimization situation according to bystanders' behavioral reactions-Focusing on the need for control, perceived control, and coping strategies, Ewha Womans University, Master's Thesis, (2013)

[12] C. H. lee, N. M. Sin, Youth Activities \& Competencies Research, National Youth Policy Institute, (2014)

[13] I. S. Oh, S. J. Kim, Y. E. Im, Moderating Effect of Collective Efficacy on the Relationship between Coping Strategies and Bystander's Reactions, Asian Journal of Education, (2019) Vol.20, No.4, pp.943-960.

[14] J. Y. Song, Experiential, Psychological, and Situational Factors Have an Influence on Bystander's Behavioral Reaction to School Bullying, Ewha Womans University, Doctorial Dissertation, (2016)

[15] J. S. Shin, Y. B. Lee, An Intervening Effect of Social Support on the Relationship of Marital Status and Life Satisfaction among Older Rural Women, Family and Family Therapy, (2007), Vol.15, No.1, pp.211-224.

[16] H. R. Lee, The parent-child relationship, child's violent tendencies, and exposure to school violence, and their co-relationship by gender, Ewha Womans University, Master's Thesis, (2007) 